\title{
New recommendations for the use of ambulatory blood pressure monitoring in the diagnosis of hypertension
}

\author{
Norm R.C. Campbell MD, Brenda R. Hemmelgarn MD PhD
}

I ncreased blood pressure is a leading risk for premature death and disability. ${ }^{1}$ It is estimated that hypertension is the most costly cardiovascular disease, with overall direct costs to health similar to that for stroke, myocardial infarction and other ischemic heart diseases combined. ${ }^{2}$ Therefore, efforts to detect and control hypertension are of great importance for public health.

Recently, the National Institute for Health and Clinical Excellence in the United Kingdom updated their recommendations for the management of hypertension. ${ }^{3}$ One of the most substantive changes to their recommendations includes the incorporation of home and ambulatory blood pressure monitoring into the diagnosis of hypertension. These guidelines recommend ambulatory blood pressure monitoring if a patient has had two elevated blood pressure readings ( $\geq 140 / 90 \mathrm{~mm} \mathrm{Hg}$ ) during an office visit. If ambulatory monitoring is not available or tolerated, home monitoring should be used. The guidelines recommend pharmacotherapy if the result of daytime ambulatory monitoring is $135 / 85 \mathrm{~mm} \mathrm{Hg}$ or higher and if there is hypertensive target organ damage, established cardiovascular disease, chronic kidney disease, diabetes or calculated cardiovascular risk of $20 \%$ or more in 10 years, or if the patient's blood pressure in the office is $160 / 100 \mathrm{~mm} \mathrm{Hg}$ or greater and the daytime ambulatory blood pressure is $150 / 95 \mathrm{~mm} \mathrm{Hg}$ or greater. Ambulatory and home monitoring are not required for diagnosis of hypertension if the patient's blood pressure is $180 / 110 \mathrm{~mm} \mathrm{Hg}$ or greater at the initial office visit and there is evidence of damage to a target organ, in which case immediate pharmacotherapy is recommended.

The National Institute for Health and Clinical Excellence notes that diagnosing hypertension using ambulatory or home blood pressure monitoring is highly cost effective, largely by avoiding hypertension diagnoses and treatment for people whose blood pressure is only elevated in physicians' offices (white coat hypertension). Ambulatory monitoring is recommended above home monitoring, likely based on their economic analy- ses, which showed cost advantages of ambulatory monitoring. However, their analysis used costs in the United Kingdom and did not account for all utility of home measurement in ongoing clinical management of hypertension. These analyses may not apply to Canada or in the context of integrating home or ambulatory techniques into the overall management of hypertension. However, their findings strongly support the increased use of ambulatory blood pressure monitoring and should stimulate discussions about government funding to provide this service.

The Canadian Hypertension Education Program has recommended since 2005 that ambulatory and home blood pressure monitoring be used in the diagnosis of hypertension, and Blood Pressure Canada has recommended home measurement of blood pressure since 1995. ${ }^{4,5}$ The Canadian Hypertension Education Program recommends further ambulatory and home blood pressure monitoring for patients with elevated blood pressure at a second office visit. Many people have reductions in blood pressure with repeat visits, with short-term increases in blood pressure secondary to the medical reason for their first office visit (related to pain or stress). The use of ambulatory blood pressure monitoring for people with elevated blood pressure at a single office visit may result in many unnecessary ambulatory recordings compared to if the decision to use ambulatory monitoring had been reassessed at a second visit.

Both the National Institute for Health and Clinical Excellence and the Canadian Hypertension Education Program recommend standard-

\section{KEY POINTS}

- Hypertension is a major preventable cause of premature death and disability.

- Physicians should assess the blood pressure of all adult patients at all relevant outpatient visits.

- Use home and ambulatory blood pressure monitoring in the diagnosis and monitoring of hypertension.

- There is uncertainty about the exact therapeutic threshold for home and ambulatory blood pressure monitoring in the range of 135-140 /85-90 mm Hg. 
ized processes and accurate equipment for assessing office, home and ambulatory blood pressure monitoring as essential parts of the diagnostic process. Information about these standardized processes for blood pressure measurement can be found at www.hypertension.ca.

Home and ambulatory blood pressure monitoring provide additional cardiovascular prognostic information to office blood pressure assessment. ${ }^{3,6}$ All techniques assess blood pressure in different settings, and office, home and ambulatory monitoring appear to provide additional prognostic information when used in combination. ${ }^{7}$ Home readings may have the additional advantages of engaging people in their care and improving adherence to medication and control of blood pressure.?

The National Institute for Health and Clinical Excellence and the Canadian Hypertension Education Program recommend a cut-off point of 135/85 mm Hg for diagnosing hypertension by home and daytime ambulatory blood pressure monitoring. ${ }^{3,4}$ The American Heart Association states that daytime ambulatory blood pressure of $140 / 90 \mathrm{~mm} \mathrm{Hg}$ or above is abnormal and that readings below 135/85 mm Hg are normal. ${ }^{8}$ The European Society of Hypertension states that daytime readings above $130-135 / 85 \mathrm{~mm} \mathrm{Hg}$ are abnormal. ${ }^{9}$ The thresholds recommended by these groups for the diagnosis of hypertension using home and ambulatory blood pressure monitoring are approximations based on estimates of blood pressure of 140/90 mm Hg obtained in an office setting in clinical trials that examined the benefits of treating hypertension. Although the 5-10/5 mm $\mathrm{Hg}$ difference in the recommendation may seem small, differences of this magnitude can result in changes to the diagnoses in over $50 \%$ of people. ${ }^{10}$ More research is needed to assess the equivalent diagnostic threshold with different techniques.

In Canada, an increasing number of physicians are using fully automated office assessment of blood pressure. The issues surrounding the diagnostic thresholds with these automated techniques are similar to those for the use of home and ambulatory blood pressure monitoring. ${ }^{11-13}$

For Canadian physicians, the message is clear. The integration of home and ambulatory blood pressure monitoring into the diagnosis and management of hypertension is desirable. Uncertainty remains about the specific therapeutic thresholds for out-of-office daytime readings in the range of 135-140/85-90 mm Hg. Decisions about treatment in the range of uncertainty could, perhaps, be based on patients' risk for vascular disease or, as the Canadian Hypertension Education Program recommends, giving the benefit of the doubt to treatment.
The Public Health Agency of Canada's Canadian Task Force on Preventive Health Care has a working group assessing the best mechanisms for screening for hypertension, and the Canadian Hypertension Education Program is developing a working group to assess the integration of the different techniques into the diagnosis and management of hypertension. Canadian health care professionals can expect more guidance in the near future. Hypertension Canada and the Canadian Hypertension Education Program have developed a website (www.hypertension.ca) where health care professionals can sign up and receive updates about new recommendations and resources for themselves and their patients.

\section{References}

1. World Health Organization. Global health risks: Mortality and burden of disease attributable to selected major risks. Geneva: The Organization; 2009. p. 1-70.

2. Heidenreich PA, Trogdon JG, Khavjou MA, et al. AHA policy statement: Forecasting the future of cardiovasular disease in the United States. Circulation 2011;123:933-44.

3. National Clinical Guidelines Centre. Hypertension: the clinical management of primary hypertension in adults. London (UK): The Centre; 2011. p. 1-310.

4. Hemmelgarn BR, McAlister FA, Myers MG, et al. The 2005 Canadian Hypertension Education Program recommendations for the management of hypertension: Part I — blood pressure measurement, diagnosis and assessment of risk. Can J Cardiol 2005; 21:645-56.

5. Campbell NRC, Abbott D, Bass M, et al. Self-measurement of blood pressure: recommendations of the Canadian Coalition for High Blood Pressure Prevention and Control. Can J Cardiol 1995; 11(Suppl H):5H-17H.

6. Quinn RR, Hemmelgarn BR, Padwal RS, et al. The 2010 Canadian Hypertension Education Program recommendations for the management of hypertension: part I - blood pressure measurement, diagnosis and assessment of risk. Can J Cardiol 2010;26: $241-8$

7. Stergiou GS, Bliziotis IA. Home blood pressure monitoring in the diagnosis and treatment of hypertension: a systematic review. Am J Hypertens 2011;24:123-134.

8. Pickering TG, Hall JE, Appel LJ, et al. Recommendations for blood pressure measurement in humans and experimental animals. Part 1: blood pressure measurement in humans. A statement for professionals from the Subcommittee of Professional and Public Education of the American Heart Association Council on High Blood Pressure Research. Hypertension 2005;45: 142-61.

9. Mancia G, De Backer G, Dominiczak A, et al. 2007 Guidelines for the management of arterial hypertension. The Task Force for the Management of Arterial Hypertension of the European Society of Hypertension (ESH) and of the European Society of Cardiolog (ESC). J Hypertens 2007;25:1105-87.

10. Campbell NRC, McKay DW. Accurate blood pressure measurement. Why does it matter? CMAJ 1999;161:277-8.

11. Myers MG, Valdivieso MA. Use of an automated blood pressure recording device, the Bp TRU, to reduce the "white coat effect" in routine practice. Am J Hypertens 2003;16:494-7.

12. Campbell NRC, Conradson HE, Kang J, et al. Automated assessment of blood pressure using BpTRU compared to assessments by a trained technician and a clinic nurse. Blood Press Monit 2005; 10:257-62.

13. Culleton BF, McKay DW, Campbell NR. Performance of the automated BpTRU measurement device in the assessment of white-coat hypertension and white-coat effect. Blood Press Monit 2006;11:37-42.

Affiliations: Departments of Medicine and Community Health Sciences, University of Calgary, Calgary, Alta.

Contributors: Both authors contributed to drafting and revising the manuscript and approved the final version submitted for publication. 